\title{
Breast Reduction for Fibrocystic Breast Disease: a case report
}

\begin{abstract}
Sultana $\mathrm{T}^{1}$, Chowdhury $\mathrm{MA}^{2}$, Hossain $\mathrm{S}^{3}$
Abstract

The pathophysiology of fibrocystic breast disease is determined by estrogen predominance that results in hyper proliferation of connective tissue (fibrosis), the risk of breast cancer is increased twofold to fourfold in these patients. The clinical correlate of fibrocystic disease is reflected by breast and axillary pain or tenderness. The disease progresses with advancing premenopausal age and is most pronounced in women during their $40 \mathrm{~s}$. We present a case of 23 years old lady who completely get rid of her symptoms from heavy breast with diagnosed fibrocystic changes immediately after breast reduction surgery. Breast reduction can be a treatment option for fibrocystic breast diseases which are not responding to medical treatment.
\end{abstract}

CBMJ 2018 July: vol. 07 no. 02 P: $42-44$

Key words: Fibrocystic disease, Preoperative Ultrasonographic (USG) measurements, NAcetyl Cysteine (NAC)

\section{Introduction}

Fibrocystic disease of breast is very common in Bangladesh and women coming for dull aching pain in all over the breast though there is no palpable lump. Women complain about their unbearable painful condition which deteriorates their lifestyle also.

We report a case of diagnosed fibrocystic diseases in both breasts with severe pain all over the breasts. We have done breast reduction for her to alleviate all her symptoms. This case report sheds light on a new treatment approach of fibrocystic diseases of breasts.

\section{Case Presentation}

A 23 years old unmarried women presented to us with large breasts for her frame with the complaints of severe pain in touch, rapid walking or jerking during traveling. She can't wear regular bra, breasts are very heavy which causes dragging pain in shoulder, back,arm and chest. She was feeling embarrassed socially and couldn't weaf the dresses she wants. She was treated previously by general surgeon conservatively for months but didn't get any improvement. Then she came to us for treatment and wants to reduce the size from 42 to 34 .

There was no palpable lump in both breast but there was tenderness in all over the breasts. No palpable axillary lymphadenopathy. We have done Preoperative Ultrasonographic (USG) measurements for diagnosis and found fibrocystic diseases in both breasts. We have planned breast reduction and took all pre-operative measurements of breasts. We have done breast Reduction with Superiomedial pedicle and inverted $\mathrm{T}$ incision under general anesthesia.

After prepping and draping, we resize the areola with cookie cutter and de-epithelialize the pedicle above the N-Acetyl Cysteine (NAC). Then we elevate the medial and lateral skin flap with wise pattern incision and incise the pedicle from below and lateral part. After mobilizing the pedicle we fix

1. Dr. Taslima Sultana, Assistant Professor, Plastic Surgery Department, National Institute of traumatology and orthopedic rehabilitation, Sher-e-Bangla Nagar, Dhaka, Bangladesh.

2. Dr. Maruf Alam Chowdhury, Associate Professor, Plastic Surgery Department, National Institute of traumatology and orthopedic rehabilitation, Sher-e-Bangla Nagar, Dhaka, Bangladesh.

3. Dr. Shakhawat Hossain, Assistant Professor Plastic Surgery Department, National Institute of traumatology and orthopedic rehabilitation, Sher-e-Bangla Nagar, Dhaka, Bangladesh.

Address of correspondence: Email: taslimasultana007@yahoo.com Mobile: 01743969739 
it with the neo NAC position. We reduce the breast tissue from lateral and inferior side and weight it. About $290 \mathrm{gm}$ was excised from each breast. Excess skin trimming done and wound closed in layers with a drain kept in situ. Specimen sent for histopathology.

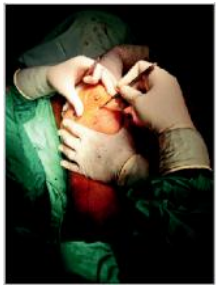

Fig 1:

Resizing the areola

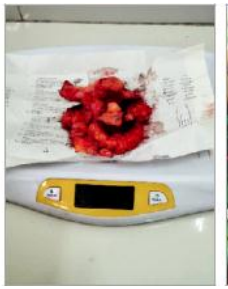

Fig 2: Excised portions of each breast

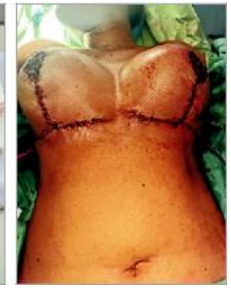

Fig 3: Peroperative
Drain removed on 3rd Postoperative Delirium (POD) and all stiches removed on $20^{\text {th }}$ POD. Her scars were little hypertrophic so we have done 2 sessions of $\mathrm{CO}_{2}$ fractional lasers.

Just after her surgery she felt relieved from pain and heaviness. She got her desired size of 34 and her lifestyle quality improved so quickly that she felt she got a new life.

We got 6 months follow-up of this patient and she is very happy with the outcome as she is absolutely pain free and gets rid of extra heaviness.

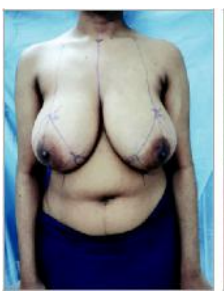

Preoperative

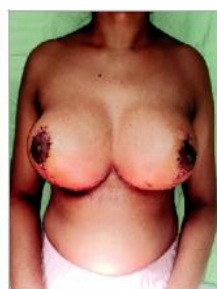

$20^{\text {th }}$ postoperative day

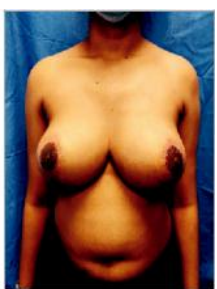

6 months later

\section{Discussion}

Fibrocystic breast disease is a very common condition and patients suffer so muchas there is no curative treatment. From our social perspective patients come lately when they can't bear the condition anymore.
Fibrocystic disease is a benign condition and tends to affect premenopsausal women between the ages of 20 and 50 . $^{7,8}$ The changes typically occur in both breasts but lumpiness and pain may be worse in one breasts than other. Gigantic breasts are typically associated with pain,but the pain and heaviness aggravates when there is fibrocystic diseases associated. Breast reduction or reduction mammoptasty is not only for reducing the volume of breast to produce aesthetically pleasing breasts but volume reduction can also reduce the amount of fibrocystic glandular tissue which eventually reduce or completely eliminate the pain and heaviness. ${ }^{1-6}$ Our patient got completely relieved from pain and other symptoms after surgery with a very comfortable and easy to carry breast size. We removed her glandular tissue of 290 gm from each breast. Histopathological report shows moderate fibrocystic changes in the resected specimen of both breasts. Postoperatively the patient felt immediate relieve of pain and heaviness after several years of sufferings and proportionate, perkier breasts. She is still on our follow up and now she passed 6 months after surgery with symptom free periods.

\section{Conclusion}

Breast reduction is an aesthetic surgery previously done for gigantomastia only but it may treat fibrocystic disease successfully dependingon the severity of the condition. Breast reduction may be the ultimate treatment of choice for benign fibrocystic breast disease presented only with pain and heaviness.

\section{Conflict of Interest: None}

\section{References:}

1. Roei $S$, Gal B, Tariq $Z$ et al. Superiomedial Pedicle Breast Reduction for Gigantic Breast Hypertrophy: Experience in 341 Breasts and Suggested Safety Modifications. Aesth Plast Surg. 2020. https://doi.org/10.1007/s00266-020-01973-y

2. Hall-Findley, Shestak KC. Breast Reduction. Plastic Recinstr Surg.2015;136(4):531e-544e 
3. Barnea $Y$, Bracha G, Arad E et al. Breast Reduction and Mastopexy for Repair of Asymmetry After Breast Conservation Therapy: Lessons Learned. Aesth Plast Surg. 2019; 43, 600-607

4. Tanaydin V, Beugels J, Andriessen A et al. Correction to: Randomized Controlled Study Comparing Disposable Negative-Pressure Wound Therapy with Standard Care in Bilateral Breast Reduction Mammoplasty Evaluating Surgical Site Complications and Scar Quality. Aesth Plast Surg. 2018; 42, 1176

5. Sisti A, Oliver JD, Huayllani MT et al. Combined Breast Reduction Augmentation. Aesth Plast Surg. 2019; 43, 878-879

6. Bitik O, Uzun H. Analysis of Lower Breast Pole Length and Nipple-Areola Complex Position Following Superior Pedicle, Short Horizontal Scar Breast Reduction. Aesth Plast Surg.2016; 40, 690-698

7. Brkic M, Vujovic S, Ivanisevic MF, Ivovic $M$, Gajic MT, Marina L, Barac M, Barac B, Djogo $A$, Malesevic $G$, Franic $D$. The Influence of Progesterone Gel Therapy in the Treatment of Fibrocystic Breast Disease.Open Journal of Obstetrics and Gynecology.2016; 6(5)

8. Vorherr H. Fibrocystic breast disease: pathophysiology, pathomorphology, clinical picture, and management. Am J Obstet Gynecol. 1986 Jan;154(1):161-79 